\title{
Neural Connections between the Nervus Intermedius and the Facial and Vestibulocochlear Nerves in the Cerebellopontine Angle: An Anatomic Study
}

\author{
R. Shane Tubbs ${ }^{1}$, MS, PA-C, PhD, Nicole Hose ${ }^{1}$, Marios Loukas ${ }^{2}$, MD, PhD, \\ Raffaele De Caro ${ }^{3}$, PhD, Aaron A. Cohen-Gadol ${ }^{4,5}$, MD, MSc
}

${ }^{1}$ Seattle Science Foundation, Seattle, WA, USA

${ }^{2}$ Department of Anatomical Sciences, St. George’s University, Grenada

${ }^{3}$ Institute of Anatomy, University of Padova, Padova, Italy

${ }^{4}$ Goodman Campbell Brain and Spine, Department of Neurological Surgery, Indiana University

School of Medicine, Indianapolis, Indiana

5. Indiana University Simon Cancer Center, Indianapolis, Indiana

\section{E-mail addresses:}

R. Shane Tubbs: shane.tubbs@chsys.org

Nicole Hose: Nicole.hose@chsys.org

Marios Loukas: mloukas@sgu.edu

Raffaele De Caro: rdecaro@unipd.it

Aaron A. Cohen-Gadol: acohenmd@gmail.com

\section{Correspondence:}

Aaron A. Cohen-Gadol, MD, MSc

This is the author's manuscript of the article published in final edited form as: Shane Tubbs, R., Hose, N., Loukas, M., de Caro, R., \& Cohen-Gadol, A. A. (2015). Neural connections between the nervus intermedius and the facial and vestibulocochlear nerves in the cerebellopontine angle. Surgical and Radiologic Anatomy. http://dx.doi.org/10.1007/s00276-015-1571-z 
Goodman Campbell Brain and Spine

Department of Neurological Surgery

Indiana University School of Medicine

355 W. $16^{\text {th }}$ Street, Suite 5100

Indianapolis, IN 46202

Phone: 317-362-8760

Fax: 317-396-1280

E-mail: acohenmd@gmail.com

\section{Funding and conflicts of interest: None}

Key words: anatomy; surgery; skull base; iatrogenic injury; ramus communicans; internal auditory meatus; facial nerve; nervus intermedius; vestibulocochlear nerve 


\begin{abstract}
Purpose: Unexpected clinical outcomes following transection of single nerves of the internal acoustic meatus have been reported. Therefore, this study aimed to investigate interneural connections between the nervus intermedius and the adjacent nerves in the cerebellopontine angle.
\end{abstract}

Methods: On 100 cadaveric sides, dissections were made of the facial/vestibulocochlear complex in the cerebellopontine angle with special attention to the nervus intermedius and potential connections between this nerve and the adjacent facial or vestibulocochlear nerves. Results: A nervus intermedius was identified on all but 10 sides. Histologically confirmed neural connections were found between the nervus intermedius and either the facial or vestibulocochlear nerves on $34 \%$ of sides. The mean diameter of these small interconnecting nerves was $0.1 \mathrm{~mm}$. The fiber orientation of these nerves was usually oblique (anteromedial or posterolateral) in nature, but 13 connections traveled anteroposteriorly. Connecting fibers were single on $81 \%$ of sides, doubled on $16 \%$ and tripled on $3 \%$, Six sides had connections both with the facial nerve anteriorly and the vestibular nerves posteriorly. On $6.5 \%$ of sides, a connection was between the nervus intermedius and cochlear nerve. For vestibular nerve connections with the nervus intermedius, $76 \%$ were with the superior vestibular nerve and $24 \%$ with the inferior vestibular nerve.

Conclusions: Knowledge of the possible neural interconnections found between the nervus intermedius and surrounding nerves may prove useful to surgeons who operate in these regions so that inadvertent traction or transection is avoided. Additionally, unanticipated clinical presentations and exams following surgery may be due to such neural interconnections. 


\section{Introduction}

The nervus intermedius carries the sensory and parasympathetic parts of the facial nerve. This small nerve has an average diameter of $0.62 \mathrm{~mm}$ and a mean length from the brainstem to the porus acousticus of $14 \mathrm{~mm}$ [1]. Historically known as the nerve of Wrisberg [7,29], the nervus intermedius can have an intimate relationship with adjacent nerves [2].

Rhoton et al. [20] described the nervus intermedius as having three parts: a

proximal segment that is adherent to the vestibulocochlear nerve, an intermediate segment that is positioned between the acoustic nerve and the motor root of the facial nerve, and a distal segment that unites with the motor root to form the facial nerve proper. These authors also found that $22 \%$ of the nervus intermedius specimens examined in their study were adherent to the vestibulocochlear nerve in the cerebellopontine angle and separated from this nerve only after the roof of the internal acoustic meatus was opened.

Various unexpected postoperative symptoms have been reported following individual manipulation of the nerves of the internal acoustic meatus. For example, Sachs [22], after sectioning the nervus intermedius, reported pain following stimulation of the vestibular nerve. The pain resolved only after sectioning the vestibulocochlear nerve. Rowed [21] blamed rogue sensory interconnecting nerve fibers that are not transected during surgical treatment of geniculate neuralgia for persistent symptoms. Morgenlander and Wilkins [15] treated one patient with cluster headaches with nervus intermedius sectioning alone, and this patient experienced postoperative deafness. In fact, Rowed [21] reported that hearing impairment is the most common serious complication following sectioning of the nervus intermedius for geniculate 
neuralgia. Moreover, cases of taste dysfunction following vestibular nerve surgery have been reported [31],

In order to investigate an anatomical reason for such unanticipated clinical presentations and exams following surgery of the nervus intermedius in the cerebellopontine angle, the present anatomic study was performed.

\section{Materials and Methods}

We used 50 adult cadaveric specimens (100 sides) with an age at death between 46 and 99 years (mean 76.5 years) that had been formalin-fixed for the present study. Twenty-nine specimens were male and 21 female. We examined the nervus intermedius from the brainstem to the porus acousticus. No specimens were found to have gross intracranial pathology. All dissections were performed under a surgical microscope (Zeiss, Germany). After a large craniotomy was performed over the posterior fossa on left and right sides, the dura mater was incised and the cerebellopontine angle entered. The facial/vestibulocochlear nerve complex was visualized and severed with microsurgical scissors as close to the brainstem as possible. Once severed on both sides, the calvaria were removed with an oscillating bone saw (Stryker, Michigan) and the brains removed and observations/and dissections made of the facial/vestibulocochlear complex in the cerebellopontine angle with special attention given to the nervus intermedius and potential connections between this nerve and the facial or vestibulocochlear nerves. When identified, random samples of such communicating branches were submitted for histologic examination (Masson Trichrome) to confirm their neural nature. Connections were measured using a microcaliper (Mitutoyo, Japan). Statistical analysis was 
performed comparing sides and gender using Statistica for Windows and significance was set at $\mathrm{p}<0.05$.

\section{Results}

A nervus intermedius was identified on all but 10 sides (6 right sides and 4 left sides). It was not separated from the vestibulocochlear nerve. On 59 sides (66\%), no connections were identified (Fig. 1). Connections were found between the nervus intermedius and either the facial (11\%) or vestibulocochlear nerves on 31 sides (34\%). The diameter of these small interconnecting nerves had a mean of $0.1 \mathrm{~mm}$ (range $0.05-0.3 \mathrm{~mm}$ ). The fiber orientation of these nerves was most often oblique (anteromedial or posteromedial) in nature (Figs. 2 and 3). However, on 4 sides (13\%; 3 left and 1 right side) the connections traveled anteroposteriorly between the nervus intermedius and adjacent nerves (Fig. 4). Connections were usually single between the nervus intermedius and either facial nerve anteriorly or vestibular nerve posteriorly. Connecting fibers were single on $81 \%$ of sides, doubled on $16 \%$ of sides and tripled on $3 \%$ of sides. Six sides had connections both with the facial nerve anteriorly and the vestibular nerves posteriorly. On 2 sides (6.5\%), the connection was between the nervus intermedius and the cochlear nerve. For vestibular nerve connections with the nervus intermedius, 74\% were with the superior vestibular nerve and 26\% were with the inferior vestibular nerve. Figure 5 shows schematically the various findings in our study. Histologically, all samples of these internervous connections were found to be neural in nature (Fig. 6). No statistical differences were identified between sides or gender. Figure 7 shows the salient findings of the various connections found.

\section{Discussion}

Peripheral nerves are known to sometimes communicate with one another [12]. Connections 
between neighboring lower cranial nerves have been reported [13,24,25,28]. However, few reports exist on the connections between the nerves of the internal auditory meatus. Oort [17] was the first to describe a connection within the internal auditory meatus between the vestibular and cochlear nerves, the so-called anastomosis of Oort. Regarding deep connections between the facial and vestibulocochlear nerves, Paturet [18] found connections between the genu of the facial nerve and Scarpa's ganglion. Cruveilhier [5] also described nerve connections between the facial and vestibulocochlear nerves and this was confirmed by later reports [8-10]. Hovelacque [11] cited Arnold two connections at the level of the porus acousticus, 1 lateral (from the facial nerve to the vestibular ganglion, with containing sympathetic fibers, 1 medial that might belong to the nervus. intermedius and connect to the vestibular nerve. This author also mentioned that Beck found each of these types as well but as single connections and that Bischoff identified two connections, the medial one from the nervus intermedius to the vestibulocochlear nerve and the lateral one from the this latter nerve to the facial nerve.

More recently and specifically, Tian et al. [27] reported vestibular to facial nerve and vestibular to cochlear nerve connections. Interestingly and historically, some investigators (e.g., von Haller, Sommering, Longet) have considered such connections to be nonexistent [23].

Within the internal acoustic meatus, Özdogmus et al. [17] reported a connection between the vestibular nerves and facial nerve, but no connections between the cochlear and facial nerves. Nageris et al. [16] noted a communication between the facial and vestibular nerves in the temporal bone in $82 \%$ of specimens. Clinically, this vestibular to facial nerve communication is a possible reason why some patients develop nystagmus following facial nerve block as a treatment of hemifacial spasm [30]. Furthermore, such connections have been implicated in the vestibular disturbance seen in patients with facial paralysis [8], Some have considered that 
persistence of vertigo in patients who have undergone cochlear nerve neurectomy might be due to connections between the cochlear and vestibular nerves [19]. Asram et al. [3] found that muscles around the mouth contracted with stimulation of the nervus intermedius, implying that this nerve might carry some motor fibers from the facial nerve. Chouard [4] recommended improving surgical outcomes in patients with Meniere's disease by transecting not only the vestibular nerve, but also any neural connecting fibers between the cochlear and facial nerves. Finally, Martin and Helsper [13] reported function of the muscles of facial expression even with complete transection of the facial nerve during removal of a parotid tumor. This reported case might lend credence to the notion that neural connections between the facial nerve and the nervus intermedius in the cerebellopontine angle might be functional connections that allow function even with injury to nerves downstream, i.e., motor fibers from the facial nerve that join the nervus intermedius in the cerebellopontine angle and travel through the geniculate ganglion and via its various branches (e.g., the greater petrosal-lacrimal branches to the upper eyelid), provide innervation to the facial muscles.

Rhoton et al. [20] did not identify a separated nervus intermedius in the cerebellopontine angle in $22 \%$ of sides in their study. The nerve was identified only after opening the internal acoustic meatus. We found the nervus intermedius in all but $10 \%$ of sides. Tarlov [26] suggested that the nervus intermedius is divisible into sensory and motor parts and that in some cases, the motor component is further separated into roots with vasodilatory and glandular secretory fibers.

Our study confirmed the presence of connections between the nervus intermedius and facial and vestibulocochlear nerves and demonstrated that these are neural in nature. Two types of fiber trajectory were noted, oblique (anteromedial and anterolateral) and anteroposterior. 
These interconnections were not always found, but when present, they could be single, doubled, or tripled.

\section{Conclusions}

Misidentifying such neural connections as found in the present study between the nervus intermedius and facial and vestibulocochlear nerves may result in inappropriate traction on a neighboring nerve with the potential for iatrogenic injury. Such connections might also make dissection between the nerves of the internal acoustic meatus more difficult. Therefore, knowledge of such branching patterns is important to the surgeon who operates in the cerebellopontine angle and may help explain certain unusual neurological findings during physical examination [6]. The functional importance of such neural interconnections between the nervus intermedius and facial and vestibulocochlear nerves remains to be determined.

\section{Conflicts of Interest}

The authors declare no conflicts of interest. No funding was received for this study.

\section{References}

1. Alfieri A, Fleischhammer J, Strauss C, Peschke E (2012) The central myelin-peripheral myelin transitional zone of the nervus intermedius and its implications for microsurgery in the cerebellopontine angle. Clin Anat. 25:882-8. 
2. Alfieri A, Fleischhammer J, Peschke E, Strauss C (2012) The nervus intermedius as a variable landmark and critical structure in cerebellopontine angle surgery: an anatomical study and classification. Acta Neurochir 154:1263-1268.

3. Ashram YA, Jackler RK, Pitts LH, Yingling CD (2005) Intraoperative electrophysiologic identification of the nervus intermedius. Otol Neurotol 26:274-279

4. Chouard CH (1975) Acousticofacial anastomoses in Meniere disorder. Arch Otolaryngol 101:296-300.

5. Cruveilhier J (1844) The Anatomy of the Human Body, edited by Pattison GS. New York: Harper \& Brothers.

6. Damodaran O, Rizk E, Rodriguez J, Lee G (2014) Cranial nerve assessment: a concise guide to clinical examination. Clin Anat 27:25-30.

7. Davis MC, Griessenauer CJ, Bosmia AN, Tubbs RS, Shoja MM (2014) The naming of the cranial nerves: a historical review. Clin Anat 27:14-19.

8. Fisch U, Esslen E (1972) Total intratemporal exposure of the facial nerve: Pathologic findings in Bell’s palsy. Arch. Otolaryngol 95:335-341.

9. Fisch UP (1973) Excision of the Scarpa’s ganglion. Arch Otolaryngol 97:147-149.

10. House WF (1961) Surgical exposure of the internal auditory canal and its contents through the middle cranial fossa. Laryngoscope 71:1363-1385.

11. Hovelacque A. Anatomie des nerfs craniens et rachidiens et du système grand sympathique. Paris, 1927, Doin Editor.

12. Ladak A, Tubbs RS, Spinner RJ (2014) Mapping sensory nerve communications between peripheral nerve territories. Clin Anat 27:681-90.

13. Liu HF, Won HS, Chung IH, Oh CS, Kim IB (2014) Variable composition of the internal 
and external branches of the accessory nerve. Clin Anat 27:97-101.

14. Martin H, Helsper JT (1957) Spontaneous return of function following surgical section or excision of the seventh cranial nerve in the surgery of parotid tumors. Ann Surg 146:715727.

15. Morgenlander JC, Wilkins RH (1990) Surgical treatment of cluster headache. J Neurosurg 72:866-871.

16. Nageris B, Braverman I, Kalmanowitz M, Segal K, Frenkiel S. (2000) Connections of the facial and vestibular nerves: an anatomic study. J Otolaryngology 29:159-161.

17. Özdogmus O, Sezen O, Kubilay U, Saka E, Duman U, Şan T, Çavdar S (2004) Connections between the facial, vestibular and cochlear nerve bundles within the internal auditory canal. J Anat 205:65-75.

18. Paturet G (1951) Traite d’Anatomie Humaine, Vol. 1. Paris: Masson et Cie.

19. Pulec JL (1995) Cochlear nerve section for intractable tinnitus. Ear Nose Throat J 74:468-476.

20. Rhoton AL Jr., Kobayashi S, Hollinshead WH (1968) Nervus intermedius. J Neurosurg 29:609-618.

21. Rowed DW (1990) Chronic cluster headache managed by nervus intermedius section. Headache 30:401-406.

22. Sachs E (1968) The role of the nervus intermedius in facial neuralgia. Report of four cases with observations on the pathways for taste, lacrimation, and pain in the face. $\mathrm{J}$ Neurosurg 28:54-60. 
23. Sachs E, Valtin EW (1977) Microscopic Analysis of the Anastomoses between the Cranial Nerves by Philipp Eduard Bischoff. University Press of New England: New Hampshire.

24. Shoja MM, Oyesiku NM, Griessenauer CJ, Radcliff V, Loukas M, Chern JJ, Benninger B, Rozzelle CJ, Shokouhi G, Tubbs RS (2014) Anastomoses between lower cranial and upper cervical nerves: a comprehensive review with potential significance during skull base and neck operations, part I: trigeminal, facial, and vestibulocochlear nerves. Clin Anat 27:118-130.

25. Shoja MM, Oyesiku NM, Shokouhi G, Griessenauer CJ, Chern JJ, Rizk EB, Loukas M, Miller JH, Tubbs RS (2014) A comprehensive review with potential significance during skull base and neck operations, Part II: glossopharyngeal, vagus, accessory, and hypoglossal nerves and cervical spinal nerves 1-4. Clin Anat 27:131-144.

26. Tarlov IM (1940) Structure of the nerve root. II. Differentiation of sensory from motor roots; observations on identification of function in roots of mixed cranial nerves. Arch Neurol \& Psychiat 1338-1355.

27. Tian GY, Xu DC, Huang DL, Liao H, Huang MX (2008) The topographical relationships and anastomosis of the nerves in the human internal auditory canal. Surgical and radiologic anatomy. Surg Radiol Anat 30: 243-247

28. Tubbs RS, Griessenauer CJ, Hogan E, Loukas M, Cohen-Gadol AA (2014) Neural interconnections between portio minor and portio major at the porus trigeminus: application to failed surgical treatment of trigeminal neuralgia. Clin Anat. 27:94-96.

29. Tubbs RS, Padmalayam D, Shoja MM, Loukas M (2014) Heinrich August Wrisberg (1736-1808): physician and anatomist. Clin Anat 27:10-3. 
30. Wakasugi B (1972) Facial nerve block in the treatment of the facial spasm. Arch Otolaryngol 95:356-359.

31. Watanabe K, Saito N, Taniguchi M, Kirino T, Sasaki T (2003) Analysis of taste disturbance before and after surgery in patients with vestibular schwannoma. J Neurosurg 99:999-1003.

\section{Figure Legends:}

Figure 1: Left-sided nerves showing no connections between the nervus intermedius (NI) and surrounding facial (VII) or vestibulocochlear nerves (VIII).

Figure 2: Left-sides nerves demonstrating a single oblique connection (arrow) between the nervus intermedius (NI) and anteriorly placed facial nerve (VII). Note the vestibulocochlear nerve (VIII).

Figure 3: Left-sided skull base noting the abducens (VI), facial (VII), nervus intermedius (NI), and vestibulocochlear (VIII) nerves and adjacent glossopharyngeal/vagus nerve complex (IX/X). The arrow marks an anteroposterior connection between the nervus intermedius and vestibulocochlear nerves.

Figure 4: Right-sided skull base near the porus acousticus and jugular foramen. Note the trigeminal (V), facial (VII), and vestibulocochlear (VIII) nerves and nervus intermedius (NI). The arrows mark the multiple interneural connections between the nervus intermedius and facial and vestibulocochlear nerves.

Figure 5: Schematic drawing of the internal acoustic meatus with percentages of nerve connection findings from left and right sides combined. 
Figure 6: Histological example $(H \& E \times 440)$ of the neural nature of the interconnections (ramus communicans) identified between the nervus intermedius and facial and vestibulocochlear nerves. A normal population of myelinated nerve fibers is seen.

Figure 7: Connections between the nervus intermedius and surrounding nerves. Abbreviations: $\mathrm{NI}=$ nervus intermedius; VIII=vestibulocochlear nerve; VII=facial nerve; SVN=superior vestibular nerve; IVN=inferior vestibular nerve. 


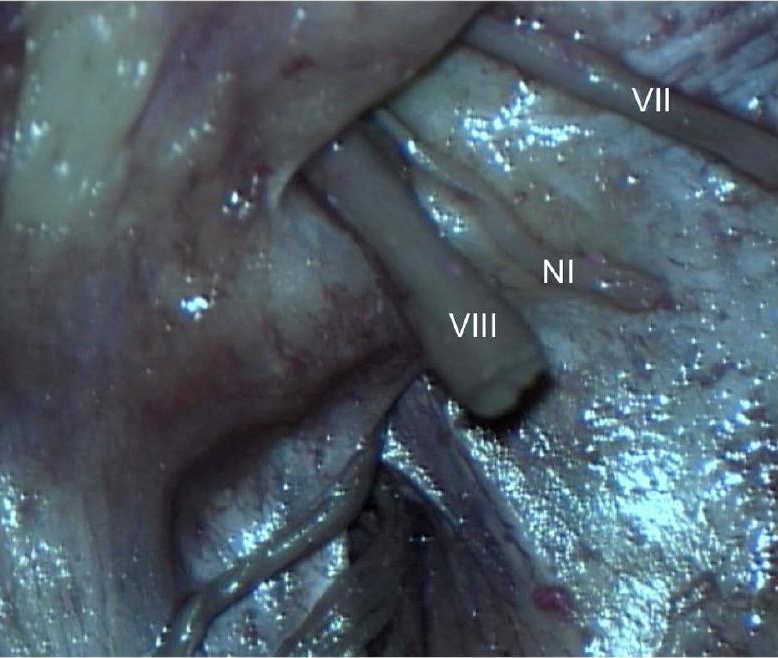




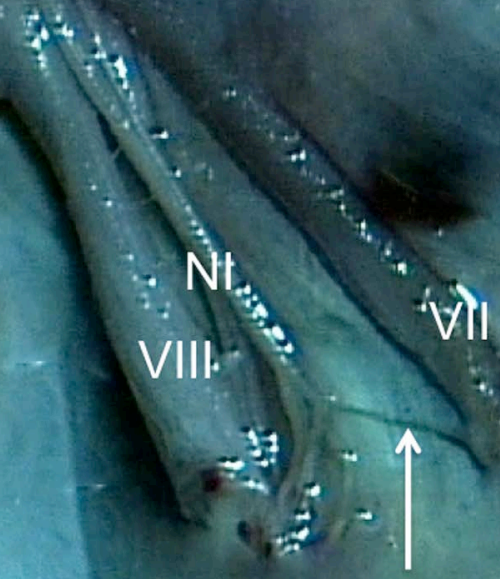


V

$y^{\prime}$

NI

VIII

VII

$\uparrow$

tot

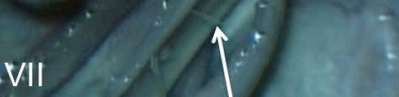




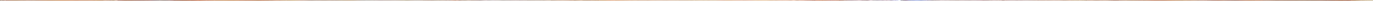




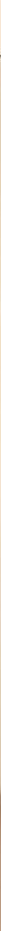


NI present on 90 sides with connections on 31 sides

Connections with VIII=21 sides
Connection with cochlear nerve $=2$
Connection with SVN=14; with $\mathrm{IVN}=5$
Connection with VII $=10$ sides 